\title{
Evaluating the antiproteinuric efficacy of cilnidipine in diabetic kidney disease
}

\author{
Taruna Sharma $^{1}$, Aalia Tausif ${ }^{1}$, Sohaib Ahmad $^{2}$
}

\author{
${ }^{1}$ Department of Pharmacology, ${ }^{2}$ Department of Medicine, Himalayan Institute of Medical Sciences, Dehradun, \\ Uttarakhand, India
}

Received: 19 October 2019

Revised: 21 November 2019

Accepted: 28 November 2019

\section{*Correspondence:}

Dr. Taruna Sharma,

Email: tarunabasera@gmail.com

Copyright: (C) the author(s), publisher and licensee Medip Academy. This is an open-access article distributed under the terms of the Creative Commons Attribution Non-Commercial License, which permits unrestricted non-commercial use, distribution, and reproduction in any medium, provided the original work is properly cited.

\section{ABSTRACT}

Background: Diabetic kidney disease is a life threatening and disabling complication of uncontrolled diabetes mellitus. Clinical proteinuria is a well-established marker of renal dysfunction. A dual L/N-type calcium channel blocker cilnidipine dilates the afferent and efferent arterioles of the glomerulus decreasing the intraglomerular pressure and showing antiproteinuric effects. The present study was conducted to assess the antiproteinuric efficacy of cilnidipine in patients of diabetic kidney disease.

Methods: This interventional study was conducted on 50 patients of both genders aged 18 years and above with diabetic nephropathy (stage-2 to stage 4) visiting the medicine OPD at HIMS, Dehradun over a period of six months, the patients were given tablet cilnidipine $(5-20 \mathrm{mg})$ once or twice a day. Baseline urine protein creatinine ratio (UPCR), serum creatinine and the estimated glomerular filtration rate (eGFR) was recorded at baseline and repeated after a period of 12 weeks. The end point was the decrease in UPCR after a period of 12 weeks. Students-paired T test was used for analysing the intragroup data.

Results: After 12 weeks of treatment with cilnidipine, a significant reduction was observed in the urinary protein creatine ratio $($ mean \pm SD) from $3.2 \pm 1.23$ at baseline to $3.09 \pm 1.09$ respectively $(p<0.05)$. Along with this there was also a reduction in the in serum creatinine which was significant $(\mathrm{p}<0.05)$ as well as an increase in the eGFR value which was also statistically significant $(\mathrm{p}<0.001)$.

Conclusions: Cilnidipine reduces the UPCR as well as improves the kidney function in patients with diabetic kidney disease.

Keywords: Cilnidipine, Diabetic kidney disease, Proteinuria

\section{INTRODUCTION}

Diabetes is one of the most common and serious metabolic disorder known to be found in almost every population all over the world non-communicable diseases globally it has become a challenging health care problem of the $21^{\text {st }}$ century, diabetes has become a leading cause of mortality in many developed countries and now there is considerable proof that it has become an epidemic in not only the developing but also the newly industrialised nations. Complications of diabetes have resulted in increased disability and reduced life expectancy with enormous health cost in virtually every society. Diabetes affects many organ systems and causes complications such as coronary artery disease, peripheral artery disease, stroke, retinopathy and renal failure. These patients are 17 times more prone to develop kidney disease which is the root cause of developing end stage renal disease (ESRD). ${ }^{1}$ Morphological and ultrastructural changes in the kidney which includes molecular matrix expansion 
and loss of charge carrier on the glomerular basement membrane as well as increased intraglomerular pressure leading to increased permeability to proteins characterise a patients of diabetic kidney disease. ${ }^{2}$ Diabetic kidney disease produces clinical proteinuria i.e. excretion of protein in urine which is a well-established marker and reliably predicts renal dysfunction even before the reduction of glomerular filtration rate (GFR). Therefore, an early diagnosis, can predict the impending renal dysfunction at initial stages of organ damage. Angiotensin converting enzyme inhibitors and angiotensin receptor blockers has showed reno protective effects in patients of diabetic kidney disease. These reduce proteinuria, delay progression, postpone renal insufficiency and improve survival. Therefore, are the first line agents for treatment. Other therapies include, conventionally used L-type calcium channel blocker (CCB) amlodipine but its reno protective effect is unsubstantial. ${ }^{3}$ Hence a new unique dihydropyridine derivative $4^{\text {th }}$ generation CCB cilnidipine having dual L/N-type calcium channel blocking property has emerged as a potential alternative to L-type blocking CCBs. Diabetic patients have increased sympathetic activity cilnidipine inhibits this activity by blocking N-type calcium channels located in the glomerulus of kidneys bringing about dilation of afferent arterioles and efferent arterioles equally, decreasing the intraglomerular pressure and showing antiproteinuric effects. ${ }^{4}$ Hence this present study is aimed to study the antiproteinuric effects of calcium channel blocker cilnidipine in patients of diabetic kidney disease.

\section{METHODS}

This interventional study was conducted by the Department of Pharmacology in collaboration with the Department of Medicine, HIMS, Dehradun from August 2018 to August 2019 after clearance granted by institutional ethics committee. A total of 50 patients attending the medicine OPD diagnosed with diabetic nephropathy with uncontrolled proteinuria were included in the study for 12 weeks after taking prior written informed consent.

The study included patients of diabetic kidney disease who satisfied all of the following requirements: men or women more than 18 years of age; patients diagnosed with diabetic nephropathy (stage-2 to stage- 4); patients with proteinuria ( $>200 \mathrm{mg} / \mathrm{dl}) ; \mathrm{HBA} 1 \mathrm{c} \geq 6.5 \%$; estimated glomerular filtration rate (eGFR) $15-90 \mathrm{ml} / \mathrm{min} / 1.73 \mathrm{~m}^{2}$; patients with serum creatinine levels $\leq 3 \mathrm{mg} / \mathrm{dl}$.

The exclusion criteria included were patients above 75 years of age; hypertensive emergencies; stroke within 3 months of start of study; patients with chronic liver disease; pregnant and lactating females; history of severe side effects of CCBs or ACE inhibitors.

The patients eligible for the study were started on cilnidipine 5-20 mg/day after which a follow up at 12 weeks was done and the blood pressure, urine protein creatinine ratio (UPCR), serum creatinine was measured and antiproteinuric efficacy was assessed. The primary end point was change in the UPCR from the pretreatment period to 12 weeks. The secondary end points included reduction in the serum creatinine, increase in the value of eGFR, indicating improvement in kidney function. In addition to this all adverse drug reactions during the study were recorded. The statistical analysis was based on standard descriptive statistical tests using the IBM SPSS version 20 software. Demographic data such as age and duration of disease is represented as mean \pm SD. The Intragroup comparison of systolic, diastolic blood pressure, serum creatinine, eGFR, UPCR and HBA1c was done using the paired students T-test the $\mathrm{p}$ value of $<0.05$ was considered significant.

\section{RESULTS}

The present study was done to assess the antiproteinuric efficacy of cilnidipine an $\mathrm{L} / \mathrm{N}$ type calcium channel blocker in patients of diabetic kidney disease. A total of 50 patients attending the medicine OPD of Himalayan Institute of Medical sciences were included in the study. There was male preponderance with 30 males and 20 females. The age of the patients ranged from 50-75 years with a mean duration of diabetes mellitus for $18.72 \pm 4.4$ years. The BMI of the patients was in the normal range $24.00 \pm 2.33 \mathrm{~kg} / \mathrm{m}^{2}$ and most of the subjects in the study were non-alcoholics and non-smokers (Table 1).

Table 1: Sociodemographic profile of diabetic kidney disease patients $(n=50)$.

\begin{tabular}{|ll|}
\hline Sociodemographic characteristics & Subjects \\
\hline Sex (male/female) & $30: 22$ \\
\hline Age (years) & $61.64 \pm 8.13$ \\
\hline Weight $\mathbf{( k g )}$ & $69.14 \pm 8.13$ \\
\hline Height $(\mathbf{m})$ & $169.60 \pm 5.49$ \\
\hline Body mass index $\left(\mathbf{k g} / \mathbf{m}^{\mathbf{2}}\right)$ & $24.0 \pm 2.33$ \\
\hline $\begin{array}{l}\text { Duration of diabetes mellitus } \\
\text { (years) }\end{array}$ & $18.72 \pm 4.4$ \\
\hline Smoker: non-smoker & $12: 38$ \\
\hline Alcoholic: non-alcoholic & $5: 45$ \\
\hline
\end{tabular}

Values are expressed in frequency and Mean \pm SD.

There was a positive correlation observed between the duration of uncontrolled diabetes mellitus and an increase in the level of proteinuria (Figure 1).

The mean systolic pressure at baseline and at 12 weeks was $147.76 \pm 21.34$ and $145.12 \pm 14.96 \mathrm{mmHg}$ respectively there was a post therapy decrease of blood pressure which was recorded but this was not found to be statistically significant. There was also no significant fall observed in the diastolic blood pressure (Table 2).

During the study duration the patients included were on oral hypoglycaemic drugs but despite this the target blood 
sugar levels were not achieved this persistent rise can demonstrate the reason leading to development of complications like diabetic nephropathy, which is clearly observed in the study (Table 3 ).

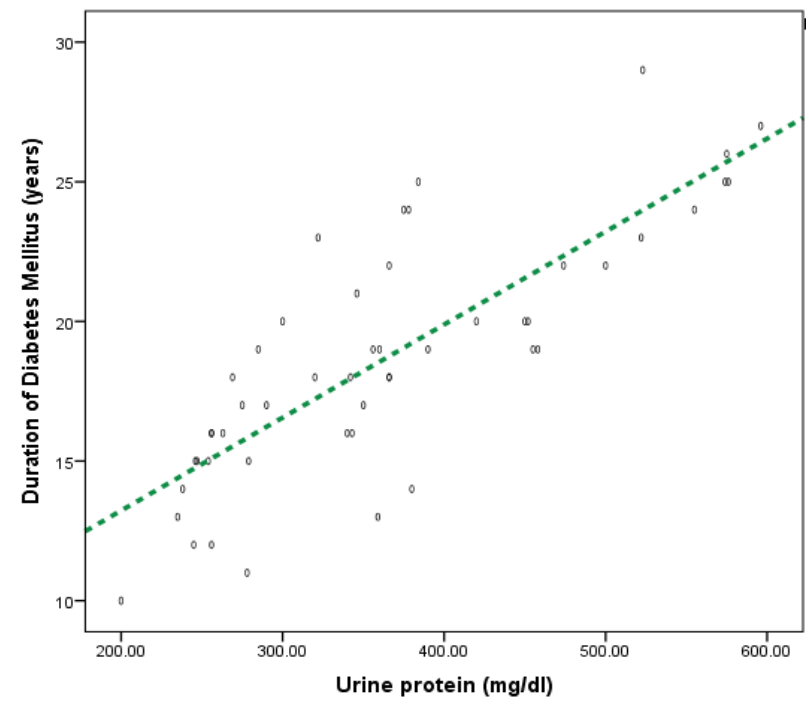

Figure 1: Correlation of proteinuria with duration of diabetes mellitus $(\mathbf{n = 5 0})$.

$\mathrm{P}<0.01$.

Table 2: Clinical characteristics of diabetic kidney disease patients $(n=50)$

\begin{tabular}{|llll|}
$\begin{array}{l}\text { Clinical } \\
\text { characteristics }\end{array}$ & $\begin{array}{l}\text { At } \\
\text { baseline }\end{array}$ & $\begin{array}{l}\text { At 12 } \\
\text { weeks }\end{array}$ & $\begin{array}{l}\text { Mean } \\
\text { change }\end{array}$ \\
\hline $\begin{array}{l}\text { Systolic blood } \\
\text { pressure (mmHg) }\end{array}$ & $147.76 \pm 2$ & $145.12 \pm$ & $2.6 \pm 6.38$ \\
\hline $\begin{array}{l}\text { Diastolic blood } \\
\text { pressure (mmHg) }\end{array}$ & $82.96 \pm 13$. & $84.1 \pm 9$. & $-1.1 \pm 3.9$ \\
\hline
\end{tabular}

Values are expressed in frequency and Mean \pm SD. Paired t-test was used for analysis *p significant is $<0.05$.

Table 3: Blood glucose profile of diabetic kidney disease patients $(n=50)$.

\begin{tabular}{|llll|}
\hline $\begin{array}{l}\text { Clinical } \\
\text { characteristics }\end{array}$ & $\begin{array}{l}\text { At } \\
\text { Baseline }\end{array}$ & $\begin{array}{l}\text { At 12 } \\
\text { weeks }\end{array}$ & $\begin{array}{l}\text { Mean } \\
\text { change }\end{array}$ \\
\hline $\begin{array}{l}\text { Fasting plasma } \\
\text { glucose (FPG) } \\
\text { (mg/dl) }\end{array}$ & $\begin{array}{l}135.78 \pm 5 . \\
17\end{array}$ & $\begin{array}{l}135.56 \pm \\
5.07\end{array}$ & $0.2 \pm 0.5$ \\
\hline $\begin{array}{l}\text { Post prandial } \\
\text { plasma glucose } \\
\text { (mg/d) }\end{array}$ & $\begin{array}{l}173.41 \pm 9 . \\
64\end{array}$ & $\begin{array}{l}173.65 \pm \\
10.01\end{array}$ & $-0.4 \pm 2.3$ \\
\hline HBA1c (\%) & $7.7 \pm 1.57$ & $\begin{array}{l}7.66 \pm 1 . \\
47\end{array}$ & $0.04 \pm 0.4$ \\
\hline
\end{tabular}

Values are expressed in frequency and Mean \pm SD. Paired t-test was used for analysis *p significant is $<0.05$.

In the study it was also observed that there was an exceptional increase in the eGFR which was statistically significant (Table 4). A reduction in the serum creatinine level was also recorded, this reduction that was observed was highly statistically significant. In addition to this a strikingly significant reduction in urine protein and an increase in the urine creatinine levels resulting in a significantly lower value of UPCR was also observed (Table 5).

Table 4: Changes in renal functions of patients with diabetic nephropathy $(\mathrm{n}=50)$.

\begin{tabular}{|lll|l|}
\hline Renal functions & $\begin{array}{l}\text { At } \\
\text { Baseline }\end{array}$ & $\begin{array}{l}\text { At 12 } \\
\text { weeks }\end{array}$ & $\begin{array}{l}\text { Mean } \\
\text { change }\end{array}$ \\
\hline $\begin{array}{l}\text { Serum creatinine } \\
\text { (mg/dl)* }\end{array}$ & $\begin{array}{l}1.39 \pm \\
0.23\end{array}$ & $\begin{array}{l}1.37 \pm \\
0.25\end{array}$ & $0.16 \pm 0.21$ \\
\hline $\begin{array}{l}\text { eGFR } \\
\left(\mathbf{m l} / \mathbf{m i n} / \mathbf{1 . 7 3} \mathbf{~ m}^{\mathbf{2}}\right) *\end{array}$ & $\begin{array}{l}65.73 \pm \\
4.88\end{array}$ & $\begin{array}{l}67.48 \pm \\
5.51\end{array}$ & $-1.7 \pm 0.6$ \\
\hline $\begin{array}{l}\text { Serum potassium } \\
\text { (mmol/l)* }\end{array}$ & $\begin{array}{l}4.67 \pm \\
0.63\end{array}$ & $\begin{array}{l}4.62 \pm \\
0.63\end{array}$ & $0.05 \pm 0.21$ \\
\hline
\end{tabular}

Values are expressed in frequency and Mean \pm SD. Paired t-test was used for analysis *p significant is $<0.05$.

Table 5: Changes in protein creatinine ratio in urine of diabetic kidney disease patients $(n=50)$.

\begin{tabular}{|llll|}
\hline & $\begin{array}{l}\text { At } \\
\text { Baseline }\end{array}$ & $\begin{array}{l}\text { At 12 } \\
\text { weeks }\end{array}$ & $\begin{array}{l}\text { Mean } \\
\text { change }\end{array}$ \\
\hline $\begin{array}{l}\text { Urine protein } \\
\text { (mg/dl)* }\end{array}$ & $\begin{array}{l}369.10 \pm \\
92.43\end{array}$ & $\begin{array}{l}365.36 \pm \\
79.64\end{array}$ & $7.78 \pm 6.8$ \\
\hline $\begin{array}{l}\text { Urine creatinine } \\
\text { (mg/dl)* }\end{array}$ & $\begin{array}{l}118.83 \pm \\
24.74\end{array}$ & $\begin{array}{l}123.06 \pm \\
24.34\end{array}$ & $-5.0 \pm 0.4$ \\
\hline $\begin{array}{l}\text { Urine protein } \\
\text { creatinine ratio* }\end{array}$ & $\begin{array}{l}3.2 \pm \\
1.23\end{array}$ & $\begin{array}{l}3.09 \pm \\
1.09\end{array}$ & $0.18 \pm 0.28$ \\
\hline
\end{tabular}

Values are expressed in frequency \& Mean \pm SD. Paired t-test was used for analysis $*$ p significant is $<0.05$.

Table 6: Adverse events reported during the study $(\mathbf{n}=\mathbf{5 0})$.

\begin{tabular}{|ll|}
\hline Adverse event & Number of subjects \\
\hline Nausea/vomiting & 3 \\
\hline Palpitations & 0 \\
\hline Pedal edema & 0 \\
\hline Urticaria & 0 \\
\hline
\end{tabular}

The adverse event that was observed during the study was nausea and vomiting. There was no complain of palpitations, pedal oedema, urticaria or angioedema that was reported (Table 6).

\section{DISCUSSION}

The following study was performed to assess the antiproteinuric efficacy of a novel fourth-generation L/N-type calcium channel blocker cilnidipine. The mean age of the study population was $61.64 \pm 10.74$ years similar to the mean age observed in another study by Hwang et al which included patients with a mean age of $61 \pm 8.5$ years. ${ }^{5}$ This might be because most of the patients enrolled in the study were diagnosed as having diabetic nephropathy developing mostly 10-15 years following the onset of 
diabetes, also a number of epidemiological studies conducted in India have shown an association between increasing age and incidence of nephropathy. ${ }^{6}$ But in comparison to these studies there are a number of other studies that have a mean age which is much lesser to our current study one such study conducted in Vatsalya hospital, Karnataka by Malleshappa had a mean age of only $44.9 \pm 13.4$ years, but this can be attributed to the small sample size of the study. There was a male preponderance observed in the study this is in accordance to a number of studies like the one conducted by Malleshappa consisting of 35 males compared to only 25 females. ${ }^{7}$ Another study by Takashi et al also consisted of 53 male and 24 female subjects. ${ }^{8}$ The difference in the prevalence of diabetic nephropathy among males and females has a very varying picture, a number of studies have observed the effects of gender on diabetic kidney disease but unfortunately these results are always contradictory, maybe due to the sample size which is small, differences in study population or methodology. The mean duration of diabetes mellitus of the subjects enrolled in the study was $18.72 \pm 4.4$ years, diabetic nephropathy is known to be a devastating microvascular complication which may begin if diabetes is poorly controlled. A gradual increase in proteinuria with an increase in duration of diabetes mellitus which was uncontrolled was observed in the following study. In the present study at enrolment the mean systolic blood pressure recorded of the patients was $147.76 \pm 21.34$ $\mathrm{mmHg}$ and the mean diastolic blood pressure was $82.96 \pm 13.23 \mathrm{mmHg}$. After addition of cilnidipine there was a reduction of $2 \mathrm{mmHg}$ in the systolic blood pressure which was not significant, the data reported in our study was similar to studies by Fukumoto et al and Malleshhappa in which there was no significant difference between the mean systolic blood pressure after treatment with cilnidipine. ${ }^{7,9}$ Similarly, there was also no significant reduction in the diastolic blood pressure which was in accordance with the data obtained in the study by Tanaka. ${ }^{10}$ Hence it can be inferred that the anti-proteinuric effect of cilnidipine is completely independent of its antihypertensive effect. In the present study the there was a reduction in the values of serum creatinine from baseline at 12 weeks, this finding observed was similar to another study done by Sarkar et al in which the suppression of serum creatinine was more in the cilnidipine group as compared to the amlodipine group. ${ }^{11}$ There was a significant increase in the mean eGFR of the patients after treatment with cilnidipine this observation is in accordance to the study done by Hwang et al in which there was significant increase in the eGFR. This increase can be attributed to a decrease in the serum creatinine levels. ${ }^{5}$ There was also a reduction in the mean UPCR after 12 weeks of treatment with cilnidipine this was in accordance to a number of studies one such study done by Fujita et al demonstrated a similar reduction in the UPCR levels. ${ }^{12}$ Another study by Kojima et al also demonstrated a decline in the UPCR levels of nearly $10 \%$ after cilnidipine treatment for a period of 6 months. ${ }^{13}$ A study by Tsuchihashi also demonstrated similar effects of reduction in UPCR. ${ }^{14}$ The reason of this decreased UPCR levels is the property of cilnidipine being a dual L/N type calcium channel blocker dilates the efferent as well as the efferent arterioles reducing the glomerular pressure and decreasing proteinuria in diabetic nephropathy preventing its progression. ${ }^{14}$ The major limitation of our study was a small sample size and a short duration of follow up of the patients, hence large cohorts, prospective studies and a longer follow up with more number of patients is required to validate the clinical significance of administering cilnidipine for treatment of proteinuria to help prevent the progression of diabetic nephropathy.

\section{CONCLUSION}

There is no permanent cure of diabetic nephropathy but renoprotective drugs like the ACEIs and ARBs are generally used to reduce the incidence of ESRD but in most cases proteinuria still persists in these patients. Therefore, since the last few years the processes and mechanisms resulting in diabetic nephropathy have been studied in large detail and henceforth new strategies have come up to prevent the progression of nephropathy. Cilnidipine has a unique dual property to block N/T-type calcium channels making it highly efficacious in reducing the levels of UPCR and preventing the progression of diabetic nephropathy. Cilnidipine was also found to be relatively safe without causing any serious side effects.

\section{ACKNOWLEDGEMENTS}

Authors would like to thank Himalayan Institute of Medical Sciences for smooth conduction of the project work. The authors are highly obliged and fortunate enough to get constant support and guidance from all the teaching members of the Department of Pharmacology, who helped in the successful completion of the project work. Above all, the authors would like to thank the clinicians from the department of medicine HIMS who helped them during their project along with the patients who gave their valuable time. The authors would also like to thank their colleagues for their immense support.

\section{Funding: No funding sources \\ Conflict of interest: None declared \\ Ethical approval: The study was approved by the Institutional Ethics Committee}

\section{REFERENCES}

1. Amos AF, McCarty DJ, Zimmet P. The rising global burden of diabetes and its complications: estimates and projections to the year 2010. Diabetic Med. 1997;14(5):7-85.

2. Sun YM, Su Y, Li J, Wang LF. Recent advances in understanding the biochemical and molecular mechanism of diabetic nephropathy. Biochemical Biophysical Res Com. 2013;433(4):359-61.

3. Ando K, Ueshima K, Tanaka S, Kosugi S, Sato T, Matsuoka $\mathrm{H}$, et al. Comparison of the antialbu- 
minuric effects of L-/N-type and L-type calcium channel blockers in hypertensive patients with diabetes and microalbuminuria: the study of assessment for kidney function by urinary microalbumin in randomized (SAKURA) trial. Int J Med Sci. 2013;10(9):1209-16.

4. Singh VK, Mishra A, Gupta KK, Misra R, Patel ML. Reduction of microalbuminuria in type-2 diabetes mellitus with angiotensin-converting enzyme inhibitor alone and with cilnidipine. Indian J Nephrol. 2015;25(6):334-8.

5. Hwang YC, Yoon KH, Cha BS, Lee KW, Jang HC, Min KW, et al. Reduction in microalbuminuria by calcium channel blockers in patients with type 2 diabetes mellitus and hypertension-A randomized, open-label, active-controlled, superiority, parallelgroup clinical trial. Int J Clin Pract. 2017;71(9):12937.

6. Varma PP. Prevalence of chronic kidney disease in India-Where are we heading? Indian J Nephrol. 2015;25(3):133.

7. Malleshappa P. Cilnidipine effectively reduces lowgrade albuminuria in hypertensive chronic kidney disease patients. Diálisisy Trasplante. 2013;34(1):2-6.

8. Masuda T, Ogura MN, Moriya T, Takahira N, Matsumoto T, Kutsuna T, et al. Beneficial Effects of L-and N-type Calcium Channel Blocker on Glucose and Lipid Metabolism and Renal Function in Patients with Hypertension and Type II Diabetes Mellitus. Cardiovascular Therap. 2011;29(1):46-53.

9. Fukumoto S, Ishimura E, Motoyama K, Morioka T, Kimoto E, Wakikawa K, et al. Antialbuminuric advantage of cilnidipine compared with L-type calcium channel blockers in type 2 diabetic patients with normoalbuminuria and microalbuminuria. Diabetes Res Clin Pract. 2012;97(1):91-8.

10. Tanaka M. The L/N-type calcium channel blocker, cilnidipine, reduces heart rate and albuminuria in patients with type 2 diabetes. J Int Med Res. 2010;38(2):602-10.

11. Sarkar S, Srivastava V, Mohanty M. Assessment of Effects of Amlodipine and Cilnidipine on Urea and Creatinine Levels in Hypertensive Patients-A Comparative Study. J Cardiol Cardiovascular Therap. 2018;10(5):1-5.

12. Fujita T, Ando K, Nishimura H, Ideura T, Yasuda G, Isshiki M, et al. Antiproteinuric effect of the calcium channel blocker cilnidipine added to reninangiotensin inhibition in hypertensive patients with chronic renal disease. Kidney Int. 2007;72(12):15439.

13. Kojima S, Shida M, Yokoyama H. Comparison between cilnidipine and amlodipine besilate with respect to proteinuria in hypertensive patients with renal diseases. Hypertens Res. 2004;27(6):379-85.

14. Tsuchihashi $\mathrm{T}$, Ueno $\mathrm{M}$, Tominaga $\mathrm{M}$, Kajioka $\mathrm{T}$, Onaka U, Eto K, et al. Antiproteinuric effect of an Ntype calcium channel blocker, cilnidipine. Clin Exp Hypertens. 2005;27(8):583-91.

Cite this article as: Sharma T, Tausif A, Ahmad S. Evaluating the antiproteinuric efficacy of cilnidipine in diabetic kidney disease. Int J Basic Clin Pharmacol 2020;9:129-33. 